\title{
Application of Ultra-High Performance Concrete in Bridge Engineering in China
}

\author{
Bao-chun Chen, College of Civil Engineering, Fuzhou University, Fuzhou, China \\ Ming-zhe An, School of Civil Engineering, Beijing Jiaotong University, Beijing, China \\ Qing-wei Huang, College of Civil Engineering, Fuzhou University, Fuzhou, China
}

Hwai-chung Wu, College of Civil Engineering, Fuzhou University, Fuzhou, China; Department of Civil \& Environmental Engineering, Wayne State University, Detroit, USA

Wen-jin Huang, College of Transportation and Civil Engineering, Fujian Agriculture and Forestry University, Fuzhou, China

Qiu Zhao, College of Civil Engineering, Fuzhou University, Fuzhou, China

\begin{abstract}
Researches and applications of UHPC have been carried out continually since late 1990s in China, especially in bridge engineering. UHPC is used widely in cover plates of cable channels, sidewalk slabs in high-speed railways, pavement on steel bridge decks, anchorage of main cables of suspension bridge, etc. Several trial designs of UHPC bridges have been conducted. Five UHPC bridges have been constructed, including two railway bridges, one highway bridge and two pedestrian bridges in China.
\end{abstract}

Keywords: Ultra-High Performance Concrete (UHPC), bridge, design, construction, application, China

\section{Introduction}

In the last three decades, China has been engaged in a large scale infrastructure construction and a lot of concrete structures have been built. As a result, China has become the largest producer of cement products and consumer of concrete products in the world. Facing more and more serious challenges including energy saving, $\mathrm{CO}_{2}$ reduction, air pollution etc., it becomes more and more conscious of the need for a wide spread adoption of high performance concrete (HPC) and ultrahigh performance concrete (UHPC).

Reactive powder concrete (RPC) as a special kind of UHPC, was introduced into China at the end of the 20th century. Researches on the preparation of UHPC using local materials have been carried out by many researchers at various universities and research institutes. Consequently, UHPC has been applied in civil engineering, especially in bridge engineering (Yan, 2015).

This paper will give a brief review on the applications of UHPC in bridge engineering in China, including those UHPC members used in bridge decks and accessories. Several trial designs of UHPC bridges and related experimental studies will be discussed, with a focus on the five completed UHPC bridges in China.

The first application of UHPC in civil engineering in China could be traced back to the voided plates (hollow slab) used in the median strip of Shijingshan Cable-stayed Bridge in Beijing to reduce the self-weight of the bridge, which was built in 2003. The plate's apparent size was $2000 \mathrm{~mm} \times 1200 \mathrm{~mm} \times 60 \mathrm{~mm}$, made of UHPC with a compression strength of $140 \mathrm{MPa}$ and flexural strength of $14 \mathrm{MPa}$ (Zheng, 2015). The plate had circular holes of $40 \mathrm{~mm}$ in diameter in 
the cross section, and could be cut with a saw (for the sake of construction convenience). After more than 10 years in service, no damage has been found and the plates are still in good shape.

In fact, the largest industrial application of UHPC was among the cover plates of cable channels and the sidewalk slabs used in China's high-speed railways since 2005. The thickness of conventional reinforced concrete $(\mathrm{C} 30)$ cable groove cover plate is $60 \mathrm{~mm} \sim 70 \mathrm{~mm}$ thick, which is too heavy and has a poor durability. Damage at the edges and corners of the plates is a common problem for conventional concrete construction, which increases the cost and slows down the construction process. The UHPC cover plate has about only one third thickness of traditional concrete cover plate, which reduces the material consumption and improves its durability. The cover plate made of UHPC with a compressive strength above $130 \mathrm{MPa}$ has a thickness of only $20 \mathrm{~mm}$, or the maximum thickness of $25 \mathrm{~mm}$ for the largest span of $744 \mathrm{~mm}$. Moreover, the conventional concrete cover plate is reinforced with steel bars while the UHPC cover plate has no steel rebar at all. About 21.4 million square meters of UHPC cover plates and about $535 \times 10^{3} \mathrm{~m}^{3}$ UHPC material has been used as of March 2015. For example, in the Zhengzhou-Xi'an Express Railway which was completed in 2007 , about $1.6 \times 10^{6} \mathrm{~m}^{2}$ UHPC cover plates had been used. A lot of UHPC baffle plates for maintenance sidewalk have also been used in high-speed railways in China. The draft technical guide of "Technological Specification for Reactive Powder Concrete (RPC) Sidewalk Baffle Plates and Cover Plates of Railways for Passengers" was issued in China in 2006 by the Ministry of Railway (China Ministry of Railway, 2006).

Another notable application of UHPC in China is in the pavement of steel bridge decks. Steel decks of highway steel bridges usually are overlaid with asphalt pavement. It is a common problem to such a structure that the flexible pavement will have large deformation and premature damage, and fatigue cracks in the orthotropic steel deck, under the directly action of vehicle loading. UHPC-steel composite deck is an effective solution to improve steel bridge's strength and stiffness (Shao, 2013). In China, researchers from Hunan University, Tongji University and Fuzhou University and several others have conducted a series of researches on this type of structures (Shao, 2013; Zhao, 2016; Guo, 2015). In 2012, the UHPC-steel composite structure was first used in the deck of Mafang Bridge, Guangdong Province, in the rehabilitation of the damaged asphalt pavement ( $\mathrm{Li}, 2015)$. At present, such kind of structural configuration has been used in designs of more than six bridges.

Another application of UHPC is in the anchor system of main cables of Aizhai Bridge. The bridge is a suspension bridge with a main span of $1176 \mathrm{~m}$, in which the main cables are anchored to the rocks. The carbon fiber composite cables are bonded to the anchorage with RPC. Such an anchorage system has good anchorage performance and workability performance, and can increase structure's durability under harsh environments (Yang, 2013).

\section{Trial Design and Experimental Research on UHPC Bridges}

\subsection{Girder Bridges}

On one hand, shallow beams are usually required in railway bridges in order to overpass highway and other obstacles. On the other hand, the impact damage caused by a train to a bridge structure increases with the train speed. Therefore, railway bridges always require larger transverse and longitudinal stiffness. It is difficult for concrete shallow girders to meet the large stiffness requirement in high-speed railway by using conventional concrete. Hence, research on shallow girders using UHPC has been proposed. Trial designs and full-scale model tests on UHPC shallow girders with a span of $20 \mathrm{~m}$ and $32 \mathrm{~m}$ were carried out, respectively. The girders with a T- 
shaped cross-section has a depth of $1.35 \mathrm{~m}$ for the $20 \mathrm{~m}$-span girder and $1.80 \mathrm{~m}$ for the $32 \mathrm{~m}$-span girder, much smaller than that of conventional concrete girder. Tests were performed on all three girders including two $20 \mathrm{~m}$-span girders and one $32 \mathrm{~m}$-span girder. Their performances were also simulated by finite element analysis (Yan, 2009; Zhong, 2012).

In 2014, Shao led a feasibility study on the design of a prestressed UHPC continuous boxgirder bridge with a main span of $400 \mathrm{~m}$ (Liu, 2014). The analysis indicated that the problems common in conventional PC box girder bridges, such as early cracking, large long-term deflection and massive weight, could be solved by using UHPC. With prosperous long-term social and economic benefits, such a new structure would be a competitive alternative to cablestayed bridge or suspension bridge with main spans varying from $300 \mathrm{~m}$ to $500 \mathrm{~m}$.

Since it is easier to find a good use of UHPC in pedestrian bridge, trial designs of UHPC pedestrian bridges were also conducted. Taking a pedestrian bridge with a main span of $47 \mathrm{~m}$ as the prototype, a trial design analysis showed that the UHPC pedestrian bridge could have a higher performance-to-price ratio, in that, the girder materials would only cost $61 \%$ of the original steel pedestrian bridge. Compared with the PC pedestrian bridge, concrete and prestress bar materials of the UHPC design will be reduced by $56.4 \%$ and $18.2 \%$ respectively, which will result in a selfweight reduction by $53.9 \%$ (Huang, 2012).

\subsection{Arch Bridges}

Arch is a natural and appropriate structural solution to bridge spanning, with impressive aesthetically pleasing and structural function. It is an ideal structure for concrete-like construction materials which have high compressive strength but low tensile strength. Many concrete arch bridges have been built in China, including the longest one in the world, the Wanxian Yangtze River Bridge that was completed in 1997 with the main span of 420m. However, construction difficulty and cost will increase rapidly due to significantly increased self-weights when the span of a bridge is over $200 \mathrm{~m}$ using concrete materials. There is a trend of using high performance concrete (HPC) in long span concrete arch bridges in the world, such as C75 HPC in the Los Tilos Bridge in Spain (built in 2004) and 70MPa concrete in the Colorado River Bridge in USA (Bao-chun, 2013).

The research group in Fuzhou University has been working on the application of UHPC in arch bridges in China since 2005. Trial designs of arch bridges with main spans of $160 \mathrm{~m}, 420 \mathrm{~m}$ and $600 \mathrm{~m}$ were carried out by using UHPC. Compared with the conventional concrete bridges, self-weights of the main arch rings were supposed to be reduced by $35 \%-42 \%$ by using UHPC. Furthermore, the construction and the inner forces of the main arch could get benefits from selfweight reduction. The trial design research indicates that it is possible to use UHPC in long span arch bridges (Renyuan, 2010).

\section{Two Railway UHPC Girder Bridges in China}

The first UHPC bridge built in China is a railway bridge, located in the Qian-Cao Railway Line, crossing over the Luanbiagangqu Dyke. It has a total of five 20m-spans, in which precast prestressed T-shape UHPFRC girders are simply supported (Gao, 2007).

The cross-section of the girder is shown in Figure 1. The depth of the girder is $1350 \mathrm{~mm}$ with a depth-span ratio of $1 / 14.8$. The thickness of the girder box web varies in the longitudinal direction. The web has a thickness of $1060 \mathrm{~mm}$ near its two end sections with a length of $870 \mathrm{~mm}$, 
Application of Ultra-High Performance Concrete in Bridge Engineering in China

a thickness of $180 \mathrm{~mm}$ at the mid-span section with a length of $3550 \mathrm{~mm} \times 2$, and a gradual thickness from $1060 \mathrm{~mm}$ to $180 \mathrm{~mm}$ for the rest sections of the box girder.

Seven 5-mm-diameter prestressing strands with the ultimate tensile strength of $1860 \mathrm{MPa}$ were placed in each duct, and the jacking stress was $1395 \mathrm{MPa}$. HRB335 steel bars with a standard tensile strength of $335 \mathrm{MPa}$ were used as reinforced bars. In every beam, there were six duct prestressing steel strands and sixteen $25 \mathrm{~mm}$ diameter reinforced bars. The average compressive strength of the UHPC standard cubic specimen was about 126.1 MPa.

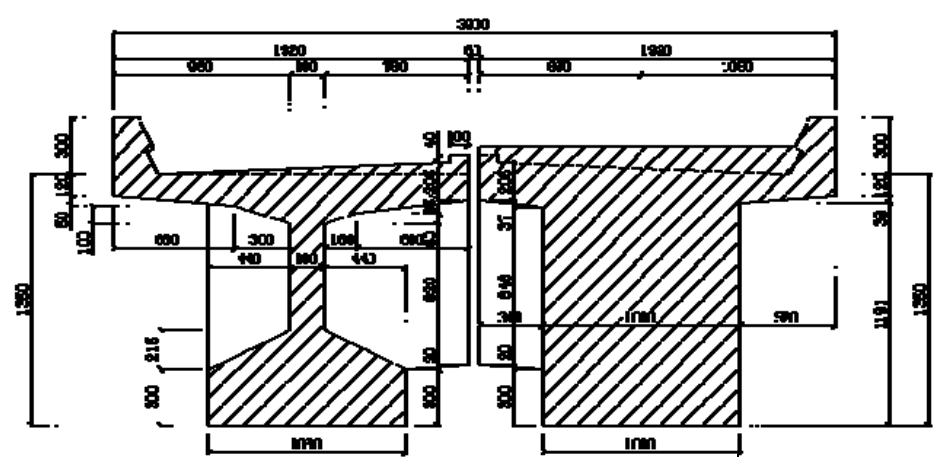

(a) Mid-span section

(b) End section

Figure 1 Cross-section of the UHPC shallow girder in Qian-Cao Railway (Unit: mm)

The second UHPC bridge in China also is a railway bridge, located in Ji-Gang Railway with a standard span of $32 \mathrm{~m}$ and a normal depth of $1800 \mathrm{~mm}$. The depth is much smaller than $2230 \mathrm{~mm}$ which is the typical depth of a conventional PC girder. The cross-section views of this shallow UHPC girder are given in Figure 2. The thickness of the girder web varies from $1060 \mathrm{~mm}$ at the end to $300 \mathrm{~mm}$ at the mid-span. The center distance between two ribs is $2.2 \mathrm{~m}$. Ribs were connected together by nine transverse diaphragms which were prestressed. Ninety-four prestressing strands with a diameter of $5 \mathrm{~mm}$ were placed in each girder. Compressive strength of the UHPC standard cubic specimen was $141.9 \mathrm{MPa}$ on average.

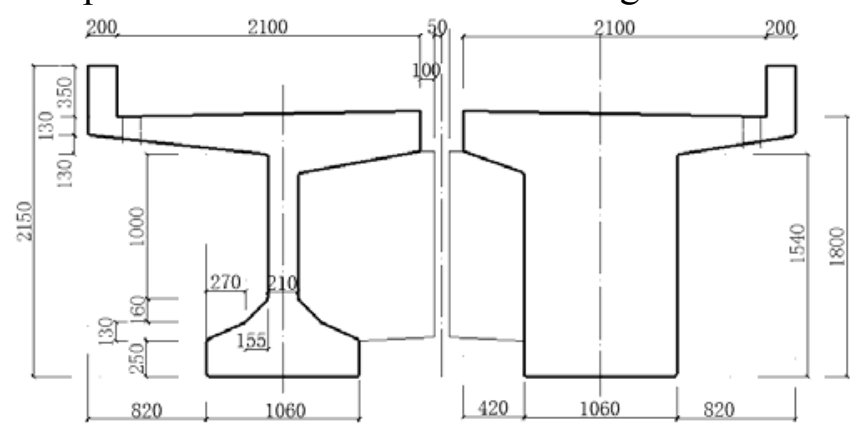

(a) Mid-span section

(b) End section

Figure 2 Cross-section of the T-shaped UHPC Shallow Girder in Ji-Gang Railway (Unit: mm)

\section{The First Highway UHPC Girder Bridge in China}

The first highway UHPC bridge in China, crossing over the express way from Beijing to Zhuhai at $\mathrm{K} 34+690$, is an overpass bridge with a span arrangement of $4 \times 30 \mathrm{~m}$. It is a skew bridge with a skew angle of $45^{\circ}$. The piers, abutments, and pile foundations are constructed by conventional 
Application of Ultra-High Performance Concrete in Bridge Engineering in China

reinforced concrete. The bridge has a deck with a width of $800 \mathrm{~cm}$, consisting of three prestressed UHPC box girders, as shown in Figure 3 (Chen, 2015).

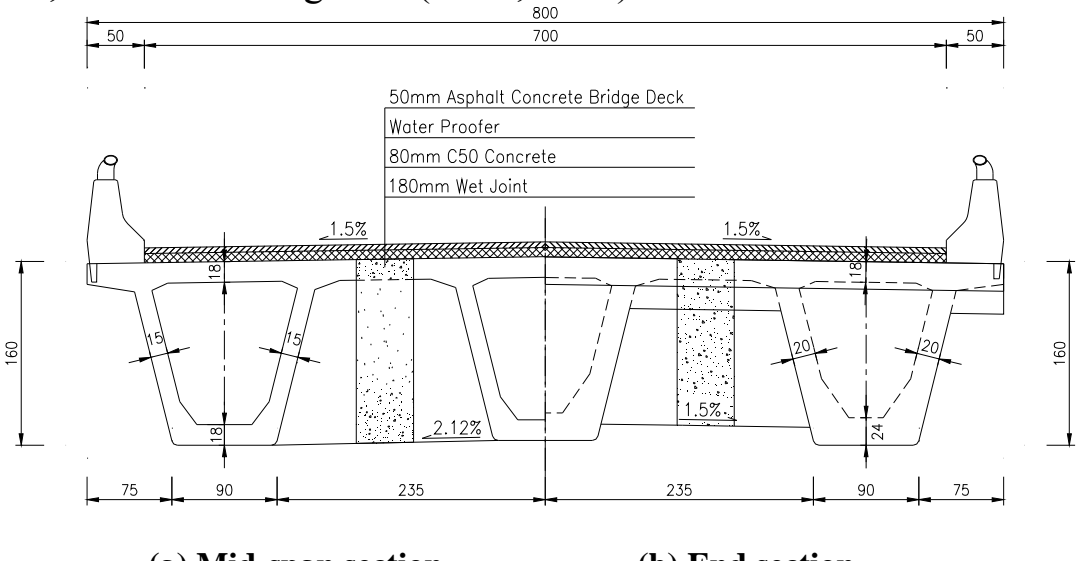

(a) Mid-span section

(b) End section

Figure 3 Cross Section of the First UHPC Highway Bridge’s Superstructure (Unit: cm)

Thirty-five prestressing strands were used in each girder. The prestressing force was obtained using 12.7-mm-diameter strands that had an ultimate tensile strength of $1860 \mathrm{MPa}$. UHPC used in the project had a compressive strength of $130 \mathrm{MPa}$ and an elasticity modulus of $40 \mathrm{GPa}$, based on $100 \times 100 \times 100 \mathrm{~mm}$ cubic specimens. The complete bridge is shown in Figure 4 .

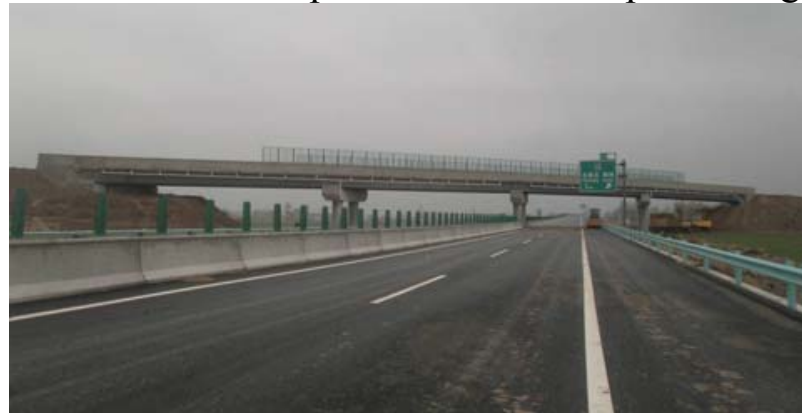

Figure 4 The First Completed UHPC Highway Bridge in China

\section{Two Pedestrian UHPC Bridges}

The first UHPC pedestrian bridge in China is an arch bridge, which is located on Fuzhou University campus. The bridge has a span of $10 \mathrm{~m}$, with a rise of $2.5 \mathrm{~m}$, giving a rise-to-span ratio of $1 / 4$. The arch axis is a segmental circle with a radius of $6.25 \mathrm{~m}$. The width of bridge is $2.1 \mathrm{~m}$. The main arch ring has a depth of $10 \mathrm{~cm}$, made of UHPC with compressive strength of $130 \mathrm{MPa}$ (Chen, 2015). The elevation view of the bridge is shown in Figure 5.

The UHPC in the arch was made without quartz powder which was replaced by the high quality local sand from Min River with particle size of $0.3-0.5 \mathrm{~mm}$. UHPC for the arch ring was produced in the structure laboratory of Fuzhou University. The arch ring was concreted on the full span centering. The arch was constructed by the cast-in-situ method with timber formwork and steel tube centering as shown in Figure 6a and the finished bridge is shown in Figure 6b. 
Application of Ultra-High Performance Concrete in Bridge Engineering in China

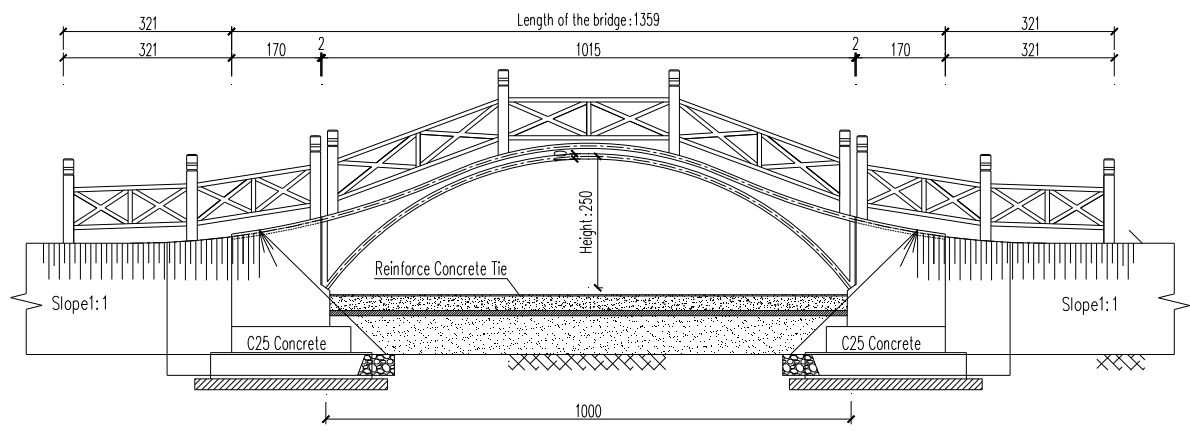

Figure 5 The Elevation of the UHPC Arch Bridge in Fuzhou University (Unit: cm)

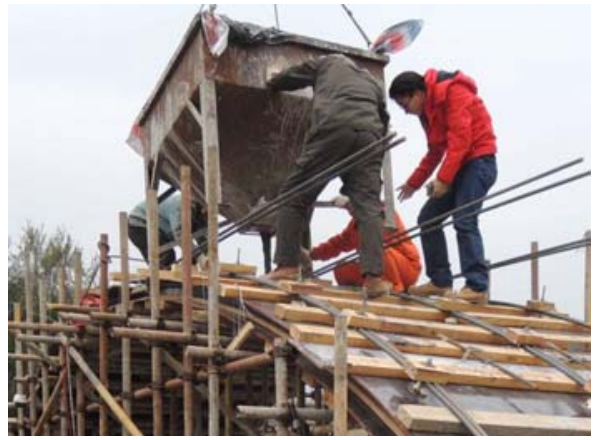

(a) Under construction

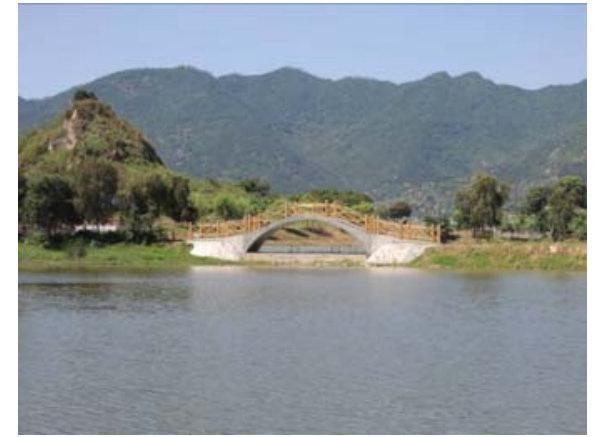

(b) completed

Figure 6 Cross Section of the UHPC Arch Bridge in Fuzhou University

The second UHPC pedestrian bridge in China is a girder bridge, which is located in Changsha, Hunan Province. The bridge has a total length of $74 \mathrm{~m}$ with a main span of $36.8 \mathrm{~m}$. The compressive strength of UHPC is $200 \mathrm{MPa}$. The precast girder was erected on site only in $10 \mathrm{~h}$. The complete bridge is shown in Figure 7 (Hong, 2016).

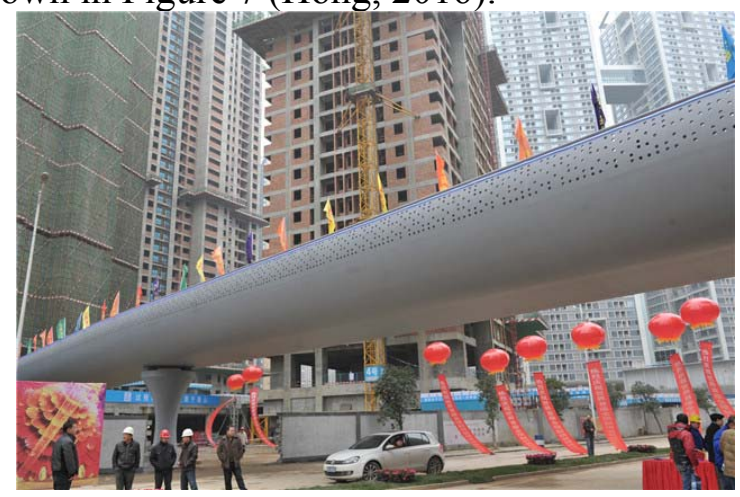

Figure 7 The UHPC Pedestrian Bridge in Changsha

\section{Conclusions}

The research and application of UHPC in bridge engineering is a hot topic in China today and have made significant achievements including five UHPC bridges completed. However, these bridges of small spans are still in the trial stage and warrant further research. A widespread implementation of UHPC bridges is still facing significant challenges ahead. 
Application of Ultra-High Performance Concrete in Bridge Engineering in China

\section{References}

Yan, P.Y., "Application of UHPC in China," Proceedings of the 1st International Symposium of ACF on Ultra High Performance Concrete, Kolkata, India, October 2015, pp. 79-82

Zheng, W.Z. and Lv, X.Y., "Literature Review of Reactive Powder Concrete," Journal of Building Structures, Vol. 36, No. 10, October 2015, pp. 44-58. (in Chinese)

China Ministry of Railway, "Technological Specification for Reactive Powder Concrete (RPC) Sidewalk Baffle Plates and Cover Plates of Railways for Passengers (Draft)," 2006. (in Chinese)

Shao, X.D., Yi, D.T., Huang, Z.Y., etc., "The Basic Performance of the Composite Deck System Composed of Orthotropic Steel Deck and Ultra-thin RPC Layer," Journal of Bridge Engineering, Vol. 18, No. 5, May 2013, pp. 417-428.

Zhao, Q., Cai, W.P. and Chen, B.C., "Shear Test Research on Smooth Plate Shear Connector of Steel and RPC Composite Deck," Journal of Chang-an University, 2016, (accepted) (in Chinese)

Guo, R., Xiao R.C. and Qu, B., "Mechanical Properties Research and Parameter Analysis on Steel-UHPC Composite Bridge Deck," Sciencepaper Online, http://www.paper.edu.cn/html/releasepaper/2015/04/463/[Published April 30, 2015]. (in Chinese)

Li, J., Wang, Y., Li, H., etc., "Research on Basic Mechanical Property of Super Highperformance Lightweight Composite Deck Pavement System," Journal of Highway and Transportation Research and Development, Vol. 32, No. 7, July 2015, pp. 55-61.(in Chinese)

Yang, X.X., "Construction Technology of CFCC Prestressed Anchor Cable for Aizhai Bridge," Construction Technology, Vol. 42, No. 5, March 2013, pp. 12-14. (in Chinese)

Yan, Z.G., Ji, W.Y. and An, M.Z., "Experimental Study and Full-Range Analysis of Reactive Powder Concrete T-Beams," Journal of Beijing Jiaotong University, Vol. 33, No. 1, February 2009, pp. 86-90. (in Chinese)

Zhong, T.Y., Liu, Z.D., Yan, Z.G., etc., "Study on the Mechanical Properties of Railway Prestressed RPC Lower Height Beam with 32m Span," China Railway Science, Vol. 33, No. 6, November 2012, pp. 11-16. (in Chinese)

Liu, Y., Shao, X.D. and Zhan, H., "Optimal Design for UHPC Continuous Box Girder Bridge with 400m Main span," Journal of Highway and Transportation Research and Development, Vol. 31, No. 8, August 2014, pp. 83-90. (in Chinese)

Huang, Q.W., Wu, Y.Y., Du, R.Y., etc., "Trial-design of a Reactive Powder Concrete Pedestrian Bridge," Journal of Guangxi University (Natural Science Edition), Vol. 37, No. 4, August 2012, pp. 751-756. (in Chinese) 
Application of Ultra-High Performance Concrete in Bridge Engineering in China

Bao-chun, C., "Recent Development and Future Trends of Arch Bridges," Proceedings of 7th International conference on arch bridges, Ed., Schmidt, M., Fehling, E., Glotzbach, C., Fröhlich, S., and Zlatko Š., Tiskara Velika Gorica, Trogir-Split, Croatia, October 2013, pp. 29-46.

Renyuan, D., Jian, Y. and Baochun, C., "Trial Design of a Reactive Powder Concrete (RPC) Arch Bridge with a Span of 420m," Proceedings of 6th International conference on arch bridges, Ed., Baochun C., and Jiangang W., New Art Color-plate \& Printing Co., LTD., Fuzhou, China, October 2010, pp. 126-132.

Gao, S.P., "Application of RPC in Railway Prestressed Prefabricated Bridge," Beton Chinese Edition-Ready-mixed Concrete, No.3, March 2007, pp. 19-21. (in Chinese)

Chen, B.C., Huang, Q.W., Shen X.J., etc., "Two Pilot UHPFRC Bridges in China," Proceedings of the 1st International Symposium of ACF on Ultra High Performance Concrete, Kolkata, India, October 2015, pp. 83-92.

Hong, D. "A UHPC Bridge was Built in Changsha," Changsha Evening Newspaper, January 11 2016, Available at http://www.icswb.com/newspaper_article-detail-171990.html.

\section{Acknowledgements}

This research described herein was sponsored in part by the National Natural Science Foundation of China under the Grant No.U1305245, No. 51578156, No. 51278039 and No. 51478120. Their supports are gratefully acknowledged. The opinions expressed in this paper are those of the authors and do not necessarily reflect the views of the sponsors. 